\title{
La pandemia COVID-19 como oportunidad de reflexión en Educación en Ciencias de la Salud
}

\author{
The COVID-19 pandemic as a reflection opportunity in Health Sciencies Education
}

Teresa Millán ${ }^{\mathrm{a}}$, Carolina Heresia ${ }^{\mathrm{a}}$, Franco Díaz ${ }^{\mathrm{b}}$, Gerardo Weisstaub $^{\mathrm{a}}$, Nelson A. Vargas ${ }^{\mathrm{a}}$

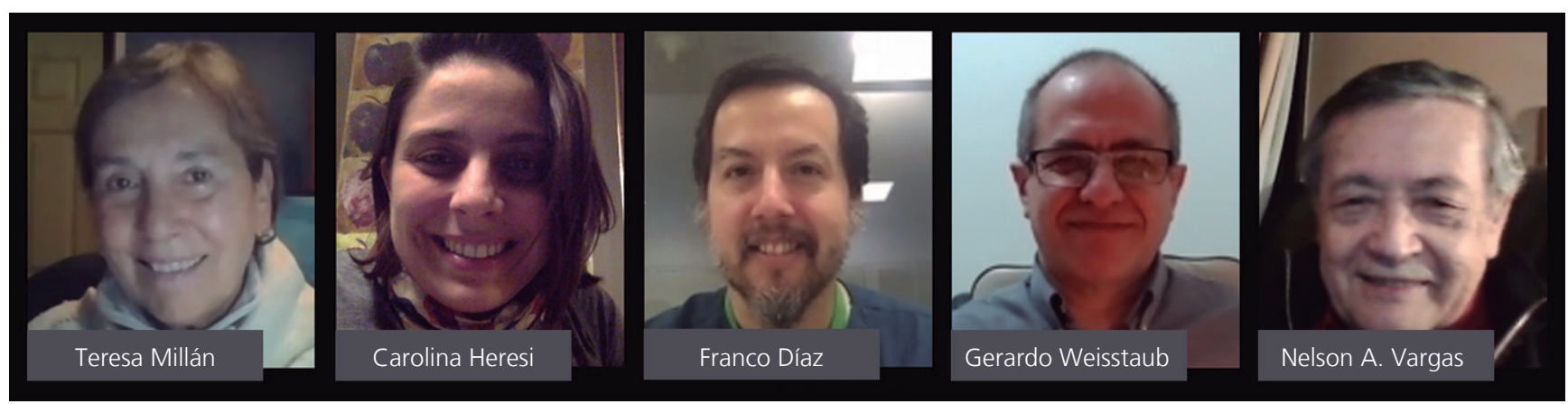

Palabras clave: COVID-19, Educación en Ciencias de la Salud, Reflexión

Keywords: COVID-19, Health Sciencies Education, Reflection

Chile y el mundo entero se encuentran viviendo una gran crisis socio-sanitaria, producto del impacto epidemiológico que ha provocado la llegada de una nueva enfermedad viral. El 30 de diciembre de 2019 en Wuhan (China) fue descrito un grupo de pacientes con falla respiratoria grave, y rápidamente en la semana siguiente se identificó al nuevo coronavirus SARS-CoV-2 como el causante de la nueva enfermedad denominada COVID-19¹ . La alta transmisibilidad del virus, así como la dinámica global contemporánea, determinaron que en los dos meses siguientes se extendiera por Asia y el resto del mundo, con una altísima morbimortalidad ${ }^{1,2}$. Como respuesta se fueron instaurando en forma progresiva medidas de distanciamiento físico, llegando finalmente a cuarentenas totales afectando a cientos de millones de personas a nivel mundial ${ }^{1,3}$.

Así comienza el cierre de puertas en los hogares y en las ciudades para protegerse, quedando sólo abiertas las de las instituciones de salud y otras actividades esenciales 4 . Junto a este brusco cambio de vida, las entidades de educación también deben cerrar sus puertas y la enseñanza presencial debe migrar a educación

Correspondencia:

Teresa Millán

tmillan@med.uchile.cl 
remota de emergencia. ¿Pero cuán preparado estábamos para esto? La verdad poco importa, bien o mal, lo imperativo es que esta violenta realidad nos obliga a continuar haciendo importantes esfuerzos creativos para mantener en movimiento el proceso educativo.

La educación remota surge a mediados del siglo XVIII en Norteamérica, con el desarrollo de herramientas entregadas a profesores y estudiantes, que se inician con formas pasivas de lectura por correo tradicional. Posteriormente, la revolución de la educación remota fue explosiva con la llegada de internet a los hogares, lo que ha permitido en la actualidad incorporar mayor reflexión, interacción y colaboración entre los participantes del proceso educativo, y desarrollo del aprendizaje centrado en el estudiante.

Sin duda estamos enfrentando una grave crisis sanitaria, pero también una gran oportunidad para generar cambios, especialmente para la Educación en Ciencias de la Salud. Los cambios van tomando cuerpo progresivamente, surgiendo iniciativas innovadoras en el marco de la educación remota de emergencia.

En las últimas décadas, el proceso de enseñanzaaprendizaje, en el ámbito de la Salud, ha ido incorporando aspectos relacionados al Constructivismo y el desarrollo de Competencias ${ }^{5,6}$, las que se entienden como el saber actuar de manera pertinente en diferentes contextos, en problemas que pertenecen a la profesión, estando en condiciones de proporcionar los argumentos que sustentan las decisiones y haciéndose cargo de sus resultados ${ }^{7}$.

Como sabemos, el aprendizaje de competencias no se limita a la enseñanza de conocimientos. Es necesario diseñar oportunidades de aprendizaje que permitan a los estudiantes desarrollar pensamiento crítico, razonamiento clínico, aprendizaje autónomo, habilidades de auto-cuidado, trabajo en equipo, profesionalismo y ética.

Si pensamos que el objetivo del proceso de enseñanza aprendizaje en tiempos de pandemia sigue siendo desarrollar competencias en los estudiantes, el desafío de los equipos académicos es enorme. Es evidente que los métodos tradicionales (fundamentalmente presenciales) no son factibles en estos tiempos y, por ahora, no podemos descansar en ellos para cumplir con los programas de formación. En estos tiempos se pueden desarrollar competencias aprovechando instancias con pacientes reales (incluyendo telemedicina), con pacientes simulados y con actividades con discusión de casos clínicos, análisis de las claves semiológicas del diagnóstico, de los elementos que aportan los exámenes de laboratorio e imagenología, de las alternativas de manejo, y discusión de los aspectos éticos y legales asociados, estimulando la participación activa de los estudiantes en formato no presencial, tanto sincrónico como asincrónico.
En este contexto, las instituciones educativas deben facilitar los medios físicos y la capacitación de los estudiantes, la totalidad de sus funcionarios y profesionales, para enfrentar los desafíos que impone la educación remota, reconociendo las necesidades pertinentes de todos los integrantes de cada comunidad educativa. Esta responsabilidad podría ser asumida, en cada institución, por una repartición específica que debería contar con recursos, disposición y actualización permanente. Así mismo, los equipos académicos deben cautelar que este proceso de cambio no implique disminuir la calidad de la enseñanza, y no sobrecargue inadecuadamente a los participantes del proceso.

Si bien la pandemia disminuye las experiencias de aprendizaje con pacientes reales, también se presenta como una oportunidad desarrollar otros ámbitos, como el manejo de la incertidumbre/crisis y la comprensión de la relevancia de los determinantes sociales en Salud. Por sobre todo, se presenta como una oportunidad de reflexionar junto a los estudiantes acerca de nuestro rol en tiempo de crisis: como personas, como ciudadanos y como futuros profesionales/especialistas. La reflexión es un proceso meta-cognitivo fundamental para comprender la realidad. Cuando está guiada por un tutor, con retroalimentación oportuna, permite a los estudiantes fundamentar sus acciones, mejorar su auto-regulación, siendo aspecto relevante en el desempeño profesional futuro y en el aprendizaje de largo plazo $^{8}$.

En el momento actual no tenemos certezas en relación a la duración de la emergencia sanitaria, que restringre las actividades asistenciales de los centros formadores. La experiencia internacional nos muestra que es posible retomar en un futuro próximo algunas actividades, instalando las medidas de protección pertinentes. Tendremos que reprogramar las asignaturas y rotaciones clínicas para contribuir a cumplir con los planes de estudios en tiempos acotados. Todo lo que aprendamos ahora sustentará la continuidad de desarrollo de competencias, cuando podamos restablecer las actividades docente-asistenciales.

Mientras nosotros estamos recién empezando el camino hacia la educación por competencias, en Estados Unidos la pandemia abrió la discusión sobre la posibilidad de organizar programas de formación de especialistas con rotaciones de duración flexible, que permitan certificar competencias de acuerdo al desarrollo particular de cada estudiante, reconociendo diferencias en el tiempo necesario para cada uno de ellos ${ }^{9}$. La experiencia de este modelo innovador podría ser considerado en el rediseño de nuestros programas de formación en el futuro.

La pandemia también es una oportunidad de reflexionar sobre las actividades que planificamos, te- 
niendo presente siempre que no sólo debemos entregar conocimiento en forma pasiva, sino oportunidades de desarrollo de competencias complejas, necesarias para el ejercicio profesional. También es una oportunidad de objetivar la necesidad de capacitación y desarrollo de nuevas competencias en los equipos académicos y de analizar los cambios que requieren los programas de formación de pre y postgrado, pensando en las competencias que necesitan los profesionales del futuro, que recojan las necesidades de una sociedad en permanente cambio.
El proceso de enseñanza /aprendizaje en el ámbito de las Ciencias de la Salud requiere hoy de un cambio profundo. Esperamos estar a la altura del desafío, y que sepamos aquilatarlo, ponerlo en marcha y aprovecharlo para el desarrollo de nuestras comunidades educativas y de la sociedad en su conjunto.

\section{Conflicto de intereses}

Los autores declaran no tener conflicto de intereses.

\section{Referencias}

1. Cevik M, Bamford C, Ho A, 2020. COVID-19 pandemic-a focused review for clinicians. Clinical Microbiology and Infection. doi:10.1016/j.cmi.2020.04.023.

2. WHO Coronavirus Disease (COVID-19) Dashboard Data last updated: 2020/6/13, 2:25pm CEST https://covid19.who.int/

3. Ambikapathy B, Krishnamurthy K. Mathematical Modelling to Assess the Impact of Lockdown on COVID-19 Transmission in India: Model Development and Validation. JMIR Public Health Surveill. 2020 May 7;6(2):e19368. doi: 10.2196/19368. PMID: 32365045 ; PMCID: PMC7207014.

4. Oficio $\mathrm{N}^{\circ} 13.556,27$ de mayo de 2020 suscrito por los Ministros del Interior y Seguridad Pública y de Defensa Nacional.

5. Carraccio C, Wolfsthal S, Englander R, Ferentz K, Martin C. Flexner Shifting Paradigms: From Flexner to Competencies. Acad Med. 2002, 77 (5): 361-367. doi: 10.1097/00001888200205000-00003.

6. Frank JR, Snell LS, Cate OT, et al. Competency-based medical education: theory to practice. Med Teach.
2010;32(8):638-645. doi:10.3109/014215 9X.2010.501190.

7. Hawes, G. \& Troncoso, K (2007) Modelo de Innovación curricular de la Universidad de Chile (2007). Pag. 12.

8. Sandars J. The use of reflection in medical education: AMEE Guide No. 44. Med Teach. 2009;31(8):685-695. doi:10.1080/01421590903050374.

9. Goldhamer MEJ, Pusic M V, Co JPT, Weinstein DF. Can Covid Catalyze an Educational Transformation? Competency-Based Advancement in a Crisis. N Engl J Med. June 2020. doi:10.1056/NEJMp2018570. 